\title{
Information Services to Support Project Activities in Distributed Large-Scale Organizations
}

\author{
Nina Bakanoval, Tatiana Atanasova ${ }^{2}$ \\ ${ }^{1}$ Keldysh Institute of Applied Mathematics - Russian Academy of Sciences, \\ Moscow, Russia \\ ${ }^{2}$ Institute of Information and Communication Technologies - Bulgarian Academy \\ of Sciences, Sofia, Bulgaria \\ Emails:nina@keldysh.ru,tatiana.atanasova@iict.bas.bg
}

\begin{abstract}
In the activities of modern project organizations, the efficiency of project implementation is a significant competitive advantage. Any project can be represented as a set of stages (for example: goal setting, detailed planning, project implementation), information on which can be found in the databases of the corporate system, which accumulates data on all types of information interaction of the organization. Corporate information systems of large organizations provide universal services to support the functioning of the systems included in its computer landscape. Principles of information flow processing are considered together with monitoring and evaluating of project activities. It is noted that the development of operational methods for analyzing the processes associated with the implementation of projects is especially important. The issues of increasing the competitiveness and success of a large-scale organization through the use of operational monitoring of project implementation are considered in the article.
\end{abstract}

Keywords: information support, information technologies, project activities.

\section{Introduction}

Large-scale distributed organizations, which are constantly in a state of reform, continually need effective information support technologies to solve urgent problems, ensure the processes of successful operation and the implementation of operational adjustments $[1,2]$. 
The success of the organization in the rapidly changing modern world is determined by the ability to initiate and implement the maximum possible (as far as the resources of the organization) number of projects. An integral factor of successful project activities is the implementation of information and methodological support at all stages of work.

Development and implementation of new methods and approaches to technologies to support project activities are relevant and in-demand tasks for distributed management structures. The solution of these problems will provide an opportunity for the organization to adapt to the conditions of the surrounding world, to maintain stable functioning and dynamic development.

The implementation of information support services in the areas and activities of a large-scale distributed organization (with the ability to detail the work before the project and a specific stage of the project) will identify successful and unsuccessful projects and activities, quickly implement corrective action, focus resources on key projects and activities. The various activities of a largescale organization and the large number of projects implemented by the organization are reflected in the information flows and business documents of the organization. The analysis of these flows allows implementing a number of information services to improve the quality of work in the areas of activity of the organization, to increase the efficiency of organizational management.

Information services to support projects and project activities based on the analysis of information flows and business documents of the organization allow timely receipt of information on project implementation and to increase the efficiency of management decisions.

\section{Information support services in the project organization}

\subsection{Principles of information flow processing}

Any project can be represented as a set of stages (for example: goal setting, detailed planning, project implementation), information on which can be found in the databases of the corporate system, which accumulates data on all types of information interaction of the organization. Corporate information systems of large organizations provide a number of universal services to support the functioning of the systems included in its computer landscape, including:

- multifunctional word processors;

- information retrieval systems;

- means of analytical data processing;

- means of intelligent data processing;

- tools for creating information systems; 
- $\quad$ powerful data storage and management tools;

- and others.

In addition, there are a number of tasks designed to support the operational modes of the organization. The software implementation of such subsystems is based on the principles of building OLTP tasks (Online Transaction Processing) real-time transaction processing.

Information support services, depending on the target tasks, are based on various methods of processing information arrays to quickly obtain the required information. The main methods used in the organization of decision support procedures in the management of large organizational structures include:

- analytical processing of information;

- $\quad$ processing and use of internal data;

- expert analysis.

Figure 1 shows possible options for using DSS (Decision Support System) methods when building management decision support subsystems in organizational management.
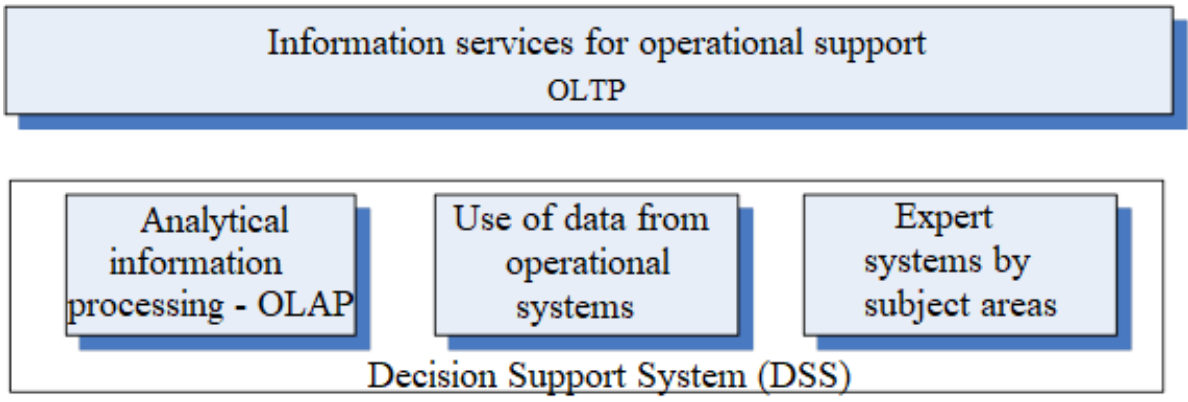

Fig. 1. Possibilities for using information services support

The group of tasks considered in this report is based on the use of internal data to implement support functions.

\subsection{Information flows processing}

All structural divisions of a large-scale distributed organization are united by common information flows. Management activities and, accordingly, project activities are carried out in accordance with information flows and are reflected in the organization's business documents.

Information flows and business documents play an important role in the management process of an organization, as they are the basis of all management activities. The information flow in the organization is a set of orders, precepts and instructions ordered in time $[3,4]$. The information flow and business documents 
reflect project activities, changes in the organizational structure, interaction with the external environment of the organization, etc. Of great interest is the analysis of the business documents of the organization, dedicated to the implementation of a specific project or set of projects. Information flows pass through the entire structure of a distributed organization - business documents for execution, implementation reports, etc. Through information flows, the distribution of work, authority and responsibility for specific projects is ensured. All changes in the course of the project are reflected in the business documents of the organization.

To monitor the organization's project activities, it is proposed to identify and investigate the characteristics of information flows related to specific projects, to analyze the relationship between the goals and objectives, the structure and number of participants carrying out project activities, the timing of implementation, both of individual stages of the project, and of the entire project in the whole.

All organizations have their own specifics and special uniqueness. The specificity and uniqueness is determined by a number of factors: the goals and objectives of the organization, management style, form of ownership, etc. In some organizations, project activities are based on a thorough and balanced approach, a comprehensive consideration of possible risks. Such organizations have a multilevel hierarchical structure, as well as a structure of powers and job responsibilities. The priority of such organizations is stability. In other organizations, project activities may not be formalized at all - projects are initiated spontaneously, managers in such organizations rely on intuition, experience and chance. Such organizations are not characterized by the presence of a multilevel hierarchical management structure. The main priorities in such organizations are profit, competitiveness, dynamism, expansion of the range of services and scope of activities [5]. This fundamental difference is due to different priorities and, as a consequence, different goals and objectives [6,7].

Thus, it can be concluded that the goals and objectives of the organization have an impact on the effectiveness of project activities and on the implementation of projects. It can also be concluded that regardless of the specifics and uniqueness of a particular organization, project activities are interconnected with information flows (with a set of business documents for the project). In other words, information flows of business documents are interconnected with the project activities of a particular organization.

The effectiveness of project activities can be assessed by the results of a project or a set of projects; it can be assessed by the degree of deviation of the results obtained from the expected (from the set goals).

Studying various methodological approaches to assessing the activities of an organization, a concept is developed for assessing the effectiveness of an 
organization. According to the concept, a model of the organization was developed as a certain system, which includes a set of blocks of primary variables: the organization's environment, goals, objectives and strategies, with the corresponding blocks of control variables. Within the framework of the concept, the following blocks of variables were provided: criteria for the internal rationality of the management apparatus, criteria for assessing the potential of the system, socio-psychological criteria for assessing the management system as a behavioural system.

Methods for assessing the organization's project activities are a reliable tool for monitoring both the execution of a specific project and the entire management activities of an organization. To monitor and analyse management activities, an assessment of project activities is required. Through the use of evaluations, it is possible to implement operational monitoring of the implementation of projects, timely identify the reasons for the low efficiency of implementation. At the next level of detail, using assessments of project activities, it is possible to monitor and analyse processes in organizational units $[8,9,10]$. In most of the methods for assessing the effectiveness of project activities, in contrast to the proposed approach, expert judgment is used. However, the expert assessment depends on the subjective opinion of experts, and the process itself is lengthy due to the need to interact with experts, the need to agree and present the results obtained.

The development of approaches and methods for monitoring project activities is an urgent problem. To solve this problem, new effective methods for analysing information flows of business documents are needed, for which it is necessary to develop criteria for evaluating project activities, criteria for searching and selecting data sources.

\section{Monitoring of project activities}

\subsection{Project activities evaluating}

To improve the efficiency of project management, it is necessary to monitor projects, analyze the effectiveness of management processes in the organization. Monitoring of project activities and analysis of the effectiveness of management processes in the organization must be carried out taking into account quantitative and qualitative indicators. As shown above, the project activities of a large-scale distributed organization are reflected in business documents, in information flows that permeate the entire organizational structure. Thus, based on the information contained in the meta-fields of business documents, it is possible to monitor the project activities of the organization with sufficient efficiency. Corporate information systems reflect information about the performing activities of the entire organization as a whole, and in terms of project activities. By extracting and 
analyzing information about the passage and execution of business documents, it is possible to monitor the implementation of projects $[1,4,8]$.

As mentioned above, monitoring the project activities of a large-scale organization requires an expert analysis of this activity, or an expert analysis of the organization's business documents related to a specific project. However, expert analysis is a lengthy and resource-intensive procedure. Even before the expert analysis, at the initial stage, it will be necessary to resolve a number of issues: assessment criteria, methods used, possible sources of data, etc. [10,11].

Therefore, in comparison with expert analysis, monitoring of project activities based on indicators and assessments extracted from corporate databases of information systems of an organization seems to be a highly effective and lowcost way of assessing an organization's activities. To conduct monitoring, it is necessary to analyse the data contained, for example, in the corporate database of the electronic document management system. The data on the basis of which to monitor project management are meta-fields and details of business documents, data from the document card about the authors, the organization - the source of the request, the progress of the document execution, results, etc. This article proposes an approach to monitoring the implementation of projects based on data contained in corporate databases of information systems (using the example of an electronic document management system). Within the framework of the proposed approach, criteria for monitoring projects, rating scales were proposed, algorithms for data analysis were proposed. On the basis of the proposed criteria, it is possible to carry out operational monitoring of the organization's project activities.

To monitor project activities, the data contained in the corporate databases of the organization's information systems must be extracted and processed using special algorithms. In the course of the described study, algorithms were developed to extract data, calculate criteria and assessments for monitoring project activities. Further, based on the calculated criteria and the obtained estimates, problem projects and areas of activity of the organization are determined. The developed approach uses:

- criteria and assessments of project activities,

- an algorithm for extracting data from corporate databases of the organization's information systems,

- an algorithm for calculating scores,

- an algorithm for analysing project activities.

To conduct monitoring, within the framework of the developed approach, the participation of experts is not required, the monitoring procedure is automated and carried out permanently. Data for estimating the criteria and assessments of project activities can be acquired from corporate databases of the organization's information systems straight during their implementation. 
The approach uses groups of qualitative criteria. Each group of qualitative criteria applies verbal grading scales. The criteria were established based on the analysis of data obtained from the information records of the corporation's files structures, in consultation with professionals and experts in the field.

As a result of data analysis, a generalized estimate is formed. The assessment is formed based on a set of features and characteristics, using a special algorithm for processing data extracted from the corporate databases of the organization's information systems. The formation of a generalized assessment is carried out using the methods of multi-criteria analysis. The development of a special algorithm and computational tools for monitoring project activities included a number of stages: analysis and research of the problem, determination of conceptual solutions, and selection of a solution. At each stage, information was required on a wide range of issues related to a specific (project) problem area.

An important factor for the implementation of monitoring modes for project activities is the identification of information sources and information retrieval. Information sources within the framework of these studies were: corporate databases, business documents and meta-fields containing information on the processing of business documents. As information sources - corporate databases, in this study, an electronic document management database was used, however, other corporate databases can also be used, since at present organizations operate a sufficient number of information systems: electronic document management systems, accounting systems, personnel management systems, project management systems and a number of others.

Figure 2 is a diagram that demonstrates the relationships and functions of an organization's corporate information system.

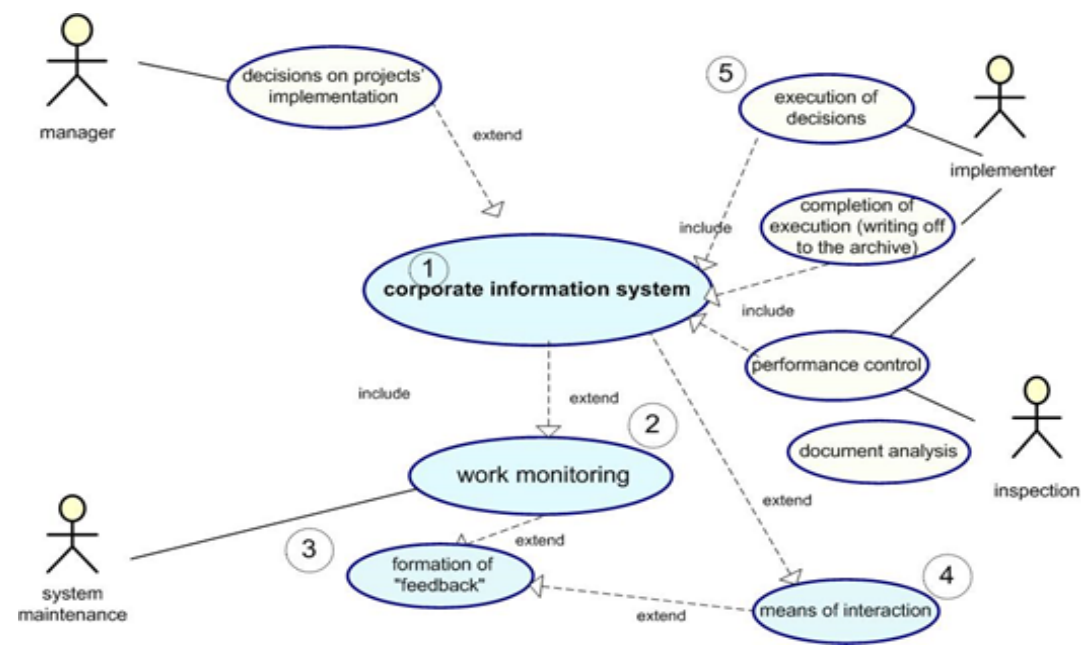

Fig. 2. Participants in the processes and functions they use. 
Execution decisions and business documents of the organization are recorded in the corporate information system of the organization. The Inspectorate controls the progress of work and monitors various areas of activity, by periods of activity, by ongoing projects.

The presented diagram visualizes the participants in the processes (actors), as well as the functions they use.

\subsection{Criteria for evaluating project activities}

The next stage in the implementation of the approach is the ranking of the prepared information arrays by problem projects or areas of activity. The ranking stage includes:

1) The choice of criteria for evaluating problem projects and the choice of sources of information, information arrays;

2) Conducting multi-criteria data analysis;

3) Ranking of the results obtained.

The chosen approach to the development of assessment criteria and scales of their gradation was determined by the task set - to use qualitative criteria with verbal grading scales focused on algorithmic assessment methods. The selection and substantiation of specific criteria was carried out on the basis of data on the specifics of the information flow, search features and methods of extracting data from corporate information systems. The developed criteria, taking into account the specifics of processing business documents, have scales that allow making assessments based on data on the passage and processing of documents.

The criteria are grouped according to the semantic relation to the attributes of the elements of the documents under study (meta-fields), to the processing processes, as well as to the data on the execution processes of business documents.

To identify problem projects in the monitoring process, criteria and grading scales for the following indicators have been determined:

1) critical characteristics of the project;

2) the significance of the project;

3) the implementation and result of the project.

Below is a list of criteria for the indicator of the significance of the project:

- The implementation period of the project;

- Linking the project upstream with business documents;

- Linking the project downstream with business documents;

- The number of requests and appeals for this project;

- Type of request and / or appeal;

- Information source;

- Directive terms of project execution; 
- The presence in the business document of references to previously made decisions on the project;

- The presence in the business document of references to regulations and orders.

On the basis of the above criteria, a multi-criteria assessment of each information array is carried out, characterizing the problem project or situation. At the next stage, using the algorithm for ranking and analysing the results, the most problematic project or area of activity is determined (as a set of similar projects).

The algorithm for evaluating and comparing projects uses the method of processing business documents of an organization, includes the use of content analysis and a specialized thesaurus. This algorithm assumes the sequential execution of the following steps:

- the first stage is the formation of a semantic digraph of links between business documents.

- the second stage is the search for paths in the digraph with subsequent analysis. The found paths are analysed with use of production rules.

The resulting estimates are used to assess the effectiveness or inefficiency of processing / execution of a business document and a related project, then the set of documents for specific performers is assessed, according to the number of errors (returns, repetitions, cycles) made by specific performers in the preparation of business documents.

The software implementation of a specialized software complex for monitoring projects and project activities implements the following functionality:

1) Performing a search for business documents and related projects, taking into account the relevance and importance of projects, choosing areas of activity and directions of the organization. As a result, a set of documents is formed, based on which projects and project activities are analysed using multi-criteria analysis algorithms.

2) Selection of sets of criteria for the analysis of selected documents.

3) A multicriteria analysis of the set of documents is carried out according to the selected list of criteria.

\section{Conclusion}

This article describes an approach to the implementation of information support services for project activities using the example of the project monitoring function of a large-scale distributed organization. The proposed approach is based on the analysis of business documents and information flows. As part of the development 
of the approach, practical research was carried out, thanks to which a specialized software package was implemented.

The advantage of the proposed approach is the possibility of integrating the developed specialized software complex into the corporate information system of the organization for the analysis of work execution processes (for example, electronic document management). Using specialized software integrated into the corporate information system, it is possible to monitor the implementation of the organization's projects, promptly obtain information about the current state of project activities, find ways to solve problems, and monitor the dynamics of project implementation.

The results of these studies open up new prospects for the development of information support services to improve the efficiency of project management processes in organizational management.

\section{References}

1. Bakanova N.B., Atanasova T.V.: Use of Information Resources of Organizational Systems to Support Managerial Decisions. In: Proc. of Int. Conference on Big Data, Knowledge and Control Systems Engineering BdKCSE'2018, 21-22 November, Sofia, Bulgaria, pp. 29-36 (2018).

2. Bakanova N., Atanasova T., Tashev T.: Using Data on Interaction Processes of Information Systems to Develop Management Decision Support Services In: Proc. of the annual conference of National Military University "Vasil Levski", Vol. 11, Veliko Tyrnovo, Bulgaria, Publishing by NVU, pp.77-82 (2019).

3. Atanasova T., Bakanova N.: Information support for decision making in organization management. In: Proc. of Int. Conference Robotics, Automation and Mechatronics'14 (RAM 2014), Prof. Marin Drinov Academic Publishing House, Sofia, Bulgaria (2014).

4. Bakanova N., Monitoring of information flows processing in distributed electronic docflow systems. Electrosvyaz, 10, 71-74 (2017).

5. Sutton R. I., Rao H.: Scaling Up Excellence, Crown Business. (2014).

6. Bakanov A., Atanasova T. and Bakanova N.: Cognitive Approach to Modeling Human-Computer Interaction with a Distributed Intellectual Information Environment, In: Proc. of International Conference Big Data, Knowledge and Control Systems Engineering'2019 (BdKCSE), Sofia, Bulgaria, pp. 1-4 (2019).

7. Bakanova N., Bakanov A., Atanasova T.: Modelling Human-Computer Interactions based on Cognitive Styles within Collective Decision-Making, Advances in Science, Technology and Engineering Systems Journal 6(1), pp. 631-635 (2021).

8. Lobanov I. A., Gudov G., Rozhnov A.: Diversification of modeling and control technology in monitoring tasks based on a retrospective example of the completion of an aerospace system operation. In: Proc. of $12^{\text {th }}$ Int. Conference Management of Large-Scale System Development MLSD'2019, Moscow (2019). 
9. Bakanov A.S., Atanasova T.V., Bakanova N.B., Tashev T.D.: Development of Monitoring Services for Analysis of Users' Requests in Distributed IS. In: Proc. of the $13^{\text {th }}$ Int. Conference Management of Large-Scale System Development, MLSD 2020, art. no. 9247676 (2020).

10. Bakanova N. B., Atanasova T. V. Method for Automated Analysis of Users' Requests to Service Centre of Information Networks in OIS. Problems of Engineering Cybernetics and Robotics 74, pp. 33-40 (2020).

11. Petrovsky A.B., "Methods for the group classification of multi-attribute objects (part 2)”. Sci. Tech. Inf. Proc. 37, 357-368 (2010). 